\title{
La reforma procesal penal en Chile: nuevos agentes, sus trayectorias y la reestructuración de un campo
}

\author{
DANIEl Palacios MuÑOZ
}

\section{Resumen}

En un contexto marcado por el fin de la dictadura, la transición democrática y a partir del estado del campo jurídico en Chile, el artículo analiza la trayectoria de los juristas que promovieron la reforma procesal penal y la estrategia que para este objetivo llevan a cabo. Estos agentes incorporan a representantes de los diversos intereses al interior del campo jurídico y, también como parte de esta estrategia, importan una expertise jurídica, brindándole de esta manera legitimidad política y técnica a sus propuestas. Esto, sumado al capital jurídico que adquieren en este proceso, permite que estos agentes puedan instalar su propuesta en la agenda de reformas a la justicia durante la transición democrática. Finalmente, se observa cómo este capital y legitimidad, que son resultado de la interacción del nivel internacional y local, les permiten participar en la transformación y estructuración del emergente espacio regional de reformas de la justicia.

Palabras ClaVe: Reforma Procesal Penal, Juristas, Campo jurídico, Expertise, Capital jurídico

\begin{abstract}
In context of the end of the dictatorship and the democratic transition, and considering the state of the legal field in Chile, this paper analyzes the trajectory of jurists who promoted the criminal law reform, as well as the strategy they used to reach this goal. This strategy included engaging representatives of the diverse interests within the legal field, as well as importing foreign expertise, giving these agents' proposals political and technical legitimacy. This, along with the legal capital they acquired during this process, enabled these agents to place their proposal on the judicial reform agenda during the democratic transition. Finally, this paper explores how this capital and legitimacy, resulting from the interaction of the local and international spheres, enabled them to participate in the transformation and reorganization of the emerging regional arena of judicial reform.
\end{abstract}

KEYWORDS: Criminal procedural reform, legal expert knowledge, judicial space, legal capital. 


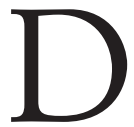
esde mediados de los años 80 en América Latina se han puesto en marcha una serie de iniciativas que forman parte de un proceso más amplio dirigido a fortalecer las instituciones jurídicas y políticas y a consolidar los procesos de democratización en la región (De la Barra, 1999: 140; Palacios, 2006: 8).

Estas iniciativas, por lo general, han sido analizadas por los mismos actores -locales e internacionales- que las han promovido y también por quienes desean abrir una discusión en torno al rumbo de tales procesos. Estos análisis, en general, se circunscriben en la discusión sobre la dirección que debiera tomar la política de reforma judicial en la región, contribuyendo de esta forma a la reproducción de este campo de reformas en Latinoamérica. Por ello son escasos los estudios que desde las ciencias sociales realizan un análisis crítico de las condiciones de posibilidad de estos intentos de reforma judicial e institucional a nivel regional (Binder y Obando, 2004:39; Faúndez y Pásara, 2007:1).

Este artículo se inscribe entre los esfuerzos ${ }^{1}$ por disminuir el vacío de las ciencias sociales en esta área analizando la reforma procesal penal en Chile ${ }^{2}$ en particular desde la perspectiva de la sociología del campo jurídico ${ }^{3}$. Este análisis nos llevará a poner en relación las estrategias específicas de los agentes que promueven la reforma con las variables estructurales en las que se enmarca este proceso y la manera en que se produce la interacción entre los niveles local e internacional. Este enfoque pretende, por una parte, distanciarse de las visiones que ponen acento sólo en los factores internos o externos al explicar estas reformas y, por otra parte, escapar a las visiones ex-post que las presentan como el producto del voluntarismo filantrópico de quienes las promueven ${ }^{4}$.

De esta forma, en primer lugar, se analizará la trayectoria inicial de los agentes que promueven la reforma procesal penal a partir de la posición que ocupaban en la estructura del campo jurídico chileno, así como del contexto político nacional marcado por el fin de la dictadura y la transición democrática. A continuación se verá cómo esta trayectoria permite, a los agentes que promueven esta reforma, insertarse en espacios institucionales desde los que podrán movilizar una serie de recursos políticos y académicos para promover esta reforma. Dicha promoción consistirá en una estrategia que, considerando la estructura del campo jurídico en esos momentos y su relación con el campo político, estará centrada en la construcción de un consenso en torno a la idea de reforma del código procesal

1 Dentro de este esfuerzo se inscriben los trabajos desarrollados por Dezalay y Garth (2002), Engelman, (2005) y Langer (2007).

2 Al igual que los otros procesos de reforma de la justicia criminal en América Latina, ésta consistió, en términos generales, en el paso desde un sistema inquisitorio a otro de carácter más acusatorio y oral. Ello trajo aparejados profundos cambios a nivel del proceso penal y a nivel orgánico e institucional. Esta reforma comenzó a implementarse en Chile por etapas entre los años 2000 y 2005.

3 Respecto de la sociología del campo jurídico recomendamos Bourdieu (1986); Dezalay y Garth (2002); Madsen y Dezalay (2002).

4 En este sentido se pretende escapar de aquello que Bourdieu (1994) identifica como "la ilusión biográfica". 
penal chileno. Como se observará en el texto, tales propuestas serán resultado de la importación de ideas del exterior y de enfoques de modernización de la política pública y del sector judicial.

Así veremos cómo en este proceso los agentes que promueven la reforma generan una expertise que es el resultado de la interacción del espacio internacional con el local, en un movimiento de ida y vuelta de construcción de un saber de Estado que se convierte en un capital que los posiciona de mejor manera en el espacio jurídico y político. Esto permitirá a estos agentes hacer competir la reforma procesal penal frente a la agenda de reformas a la justicia elaborada por el gobierno chileno y con aquella que financiaba la cooperación norteamericana. En este sentido constataremos la manera en que esta reforma es capaz de desplazar a una agenda que correspondía en esos momentos a las estrategias de reproducción del poder de Estado en el país.

Por último, se mostrará cómo los agentes que promueven la reforma procesal penal terminan por posicionarse en el espacio nacional e internacional de expertos en reforma judicial, movilizando el capital y expertise generados en este proceso local.

\section{El campo jurídico en la Transición Democrática y los gestores de la reforma procesal penal}

Para comprender el proceso de reforma procesal penal chileno, desde una perspectiva de la sociología del campo jurídico, resulta útil analizar las trayectorias individuales de sus agentes promotores a la luz de la posición que ocupaban en el campo jurídico, en un contexto político marcado por el fin de la dictadura y la transición democrática (fines de la década de los años 1980 a principios de los 90).

En esta sección se mostrará que la reforma procesal en Chile es promovida por actores que, al inicio de su trayectoria, se ubicaban al margen de las posiciones dominantes en el campo jurídico nacional, pero que, posteriormente, logran incorporarse en el espacio de los agentes jurídicos que participan de la transición democrática en Chile. Y como se verá, a partir de tal incorporación estos agentes acceden a un capital jurídico y político que podrán movilizar en la promoción del proceso de reforma procesal penal.

Los dos agentes que tuvieron un rol fundamental en la promoción de la reforma son Juan Enrique Vargas y Cristián Riego. Se trata de dos juristas que realizan sus estudios al mismo tiempo en la Facultad de Derecho de la Universidad de Chile, finalizándolos en los últimos años de la dictadura de Pinochet ${ }^{5}$. La opción de Riego por los estudios de derecho nació más bien de un interés difuso por las

5 A partir del plebiscito de 1988 el gobierno militar debió convocar a una elección en 1989, que tuvo como resultado la entrega del mando presidencial por parte de Augusto Pinochet a Patricio Aylwin en marzo de 1990. 
ciencias sociales y humanidades y de la percepción generalizada, en aquel entonces, del derecho como "la disciplina de las humanidades y ciencias sociales" con mayor área de desempeño que aseguraba una inserción profesional ${ }^{6}$. En el caso de Vargas, el interés general por las humanidades va acompañado, a su vez, de una cierta cercanía a nivel familiar con el mundo del derecho ${ }^{7}$. Ahora bien, la opción de ambos por los estudios de derecho no se puede entender como parte de una estrategia de reproducción social como lo era en el caso de la elite jurídica tradicional en Chile (Dezalay y Garth, 2002: 55 y 311$)^{8}$, puesto que para ambos esta opción no estaba aparejada a un proyecto predefinido de inserción laboral.

Al momento que ambos realizaban sus estudios de derecho (a mediados de la década de 1980) el espacio académico de las universidades estaba ocupado por juristas tradicionales que encarnaban la ortodoxia jurídica, siendo éstos principalmente juristas cercanos al poder judicial y también miembros de este poder. Pero al mismo tiempo, una parte de la comunidad jurídica marginada de las universidades tradicionales durante la dictadura criticaba a este grupo tradicional: éstos consideraban que la actividad académica de los sectores tradicionales era limitada y que respondía a los intereses de este grupo que trataba de cuidar su posición, reproduciendo sus prácticas tradicionales y por tanto excluyendo toda reflexión crítica $^{9}$. A esto se le sumaba que los juristas que dominaban el espacio de las universidades tradicionales, y en particular la magistratura, en su mayoría, eran identificados como colaboradores o a lo menos sujetos pasivos frente al régimen dictatorial en Chile (sobre el rol de la magistratura durante la dictadura militar ver Hilbink, 2007).

Esta falta de espacios e inconformidad con el mundo jurídico tradicional dominante en la universidad, llevó a Riego y Vargas a buscar otras opciones. Así, a mediados de la década de los 80, siendo estudiantes aún, Riego y Vargas con un

6 Entrevistas realizadas en noviembre 2007. Habría que agregar que durante la dictadura las opciones de estudio en ciencias sociales eran bastante reducidas, dada la intervención profunda de que fueron objeto. Esto llevó incluso a que la enseñanza de ciertas disciplinas fuera cancelada en algunas universidades (como la sociología por ejemplo). Sobre la situación de las ciencias sociales en Chile durante la dictadura ver Puryear, 1994.

7 Sin provenir de una familia tradicional del mundo del derecho, en su familia el derecho estaba presente con su hermana y abuelo paterno abogados.

8 Como la estrategia de reproducción familiar de las elites en el mundo de los estudios jurídicos. O como en el caso de la tradicional elite de Estado hasta los años 60, cuyo inicio de trayectoria estaba ligado a su paso por la Facultad de Derecho de la Universidad de Chile.

9 Para muchos, la educación legal en Chile estaba orientada tradicionalmente hacia el método exegético, que privilegiaba la memorización de leyes y códigos. De esta manera tanto estudiantes como jueces debían pensar y abordar la ley tomando en cuenta lo que decían los códigos y los libros, considerando a la figura del legislador como la única fuente de la ley (Hilbink, 2007: 36). Por este motivo "la ciencia del derecho" no contribuía a su propia evolución. Esta situación potenciaba, a su vez, el fenómeno de exclusión del derecho de los procesos de renovación que se daban en otros dominios (Dezalay y Garth, 2002:341) y que habían comenzado a darse en Chile a partir de los proyectos desarrollistas de los años '60 con la preeminencia de otras disciplinas, como la economía y la sociología; al respecto ver Dezalay y Garth (2002); Peña (1992). Para un análisis crítico respecto de la actividad de los abogados, del estado de la enseñanza del derecho y de la falta de una comunidad académica profesional, ver Peña et al. (1994). 
grupo de compañeros ${ }^{10}$ comienzan a asistir a una serie de cursos que se impartían en la Academia de Humanismo Cristiano (AHC). Esta institución fue creada por la iglesia católica en 1975, y brindó un espacio institucional a los investigadores y académicos expulsados de las universidades tradicionales durante la dictadura ${ }^{11}$. Este espacio permitió el encuentro de intelectuales cercanos a la democracia cristiana y a la izquierda moderada, en el marco de libertad intelectual para el desarrollo de la investigación y la actividad académica, quienes comienzan a realizar una crítica académico-política a la dictadura. Así la AHC se fue constituyendo en uno de los espacios donde se comienza a delinear la transición democrática ${ }^{12}$ y se generan los encuentros entre los distintos grupos que darán origen a la Concertación de Partidos por la Democracia ${ }^{13}$.

En el caso de Cristián Riego este contacto con la AHC se tradujo en su incorporación en un programa de postítulo en sociología y economía que daba el Programa de Estudios del Trabajo (PET) ${ }^{14}$ y que contaba con la participación de profesores extranjeros. Además, un par de años antes, Riego había comenzado a participar de un grupo de estudiantes que conducía Sergio Yáñez, un profesor que se mantenía en la Universidad de Chile y que formaba parte de los profesores de derecho penal que continuaban con la tradición académica e intelectual ${ }^{15}$ propia de esta área. A partir de esto Riego se transformó en ayudante de Yáñez (1984-1985), introduciéndose así en el derecho penal. Por medio de este último, Riego conoce a Jorge Mera quien había sido expulsado de la Universidad de Chile, y a Juan Bustos, quien había estado en el exilio, los que serán posteriormente importantes en la trayectoria de Riego y otros juristas que participaron en la gestación de la Reforma Procesal Penal en Chile (de ahora en adelante RPP). Esto

10 Este grupo estaba formado por Juan Enrique Vargas, Cristián Riego, María Inés Horvitz, José Miguel Vivanco y Felipe González. Los tres primeros participarán directamente en la reforma procesal penal. Por su parte Vivanco y González participarán posteriormente del campo internacional de DDHH.

11 En la AHC se generaron programas de investigación sobre economía y trabajo, actitudes políticas y desarrollo, Derechos Humanos, desarrollo agrario y educación.

12 Sobre los intelectuales y los centros de investigación durante la dictadura y su rol en la transición democrática ver: Puryear (1994); Dezalay y Garth (1998; 2002).

13 Coalición política que se formó para hacer oposición al régimen del General Pinochet en el plebiscito de 1988. Desde la caída de la dictadura en Chile, esta coalición ganó cuatro elecciones presidenciales (en 1989 con Patricio Aylwin, en 1993 con Eduardo Frei Ruiz-Tagle, en 1999 (segunda vuelta en 2000) con Ricardo Lagos y en el año 2005 con Michelle Bachelet). Esta coalición está formada por: Partido Socialista, Partido Radical Socialdemócrata, Partido por la Democracia y por el Partido Demócrata Cristiano. De aquí en adelante Concertación.

14 Este centro fue uno de los espacios principales para los economistas de la izquierda. Esencialmente se dedicaba a la economía del trabajo pero también tenía un programa de asesoría y asistencia directa a organizaciones populares. Además este centro entregaba su opinión sobre el funcionamiento de la economía durante la dictadura (Puryear, 1994: 117).

15 Durante la dictadura en el área del derecho penal quedaban dos profesores que se dedicaban a mantener un trabajo intelectual y que no habían sido expulsados de las universidades tradicionales como sus colegas. Éstos eran Enrique Cury en la Universidad Católica y Sergio Yáñez en la Universidad de Chile. Este último, en esos momentos, estaba de acuerdo con el golpe militar y pudo continuar trabajando en la Universidad de Chile, sin embargo para Riego éste era un "liberal". Una gran parte de los penalistas de la generación de Riego que se dedican a la enseñanza del derecho penal fueron formados por Cury y Yáñez (entrevista realizada en noviembre 2007). 
fue posible pues el mundo del derecho penal en esos momentos era reducido y todos los penalistas se conocían entre $\mathrm{si}^{16}$.

Esta trayectoria inicial es importante en el caso de Riego, pues cuando se produce la transición democrática él ya se había introducido en el mundo del derecho penal y tenía nociones de la economía y sociología que le permitieron "tener una visión más empírica sobre el sistema", que era "bastante novedosa pues los juristas no tenían esa visión"17.

En el caso de Vargas, éste comienza a participar en talleres informales sobre Derechos Humanos y justicia junto con el grupo de estudiantes que buscaba otros espacios de formación a los entregados por la Universidad de Chile. En estos talleres Jorge Mera cumplía el rol de monitor de las reflexiones de este grupo de estudiantes. Además, Vargas participaba de todas las oportunidades de formación que le ofrecía el Programa de Derechos Humanos de la AHC del cual el mismo Jorge Mera era su director.

A partir de estos contactos iniciales, en 1986 Vargas comienza a trabajar como ayudante en el Programa de Derechos Humanos de la AHC. Él reemplaza a su amigo José Miguel Vivanco, quien parte de Chile y establece el nexo directo entre Vargas y Jorge Mera. Este trabajo se le presenta a Vargas como una oportunidad de realizar alguna actividad académica, pues, dada la situación de la Universidad de Chile, para Vargas era imposible pensar en poder desarrollar una actividad académica en la misma facultad en que realizó sus estudios.

El programa que dirigía Mera y en el que Vargas se incorpora tenía como objetivo el análisis de las diferentes salidas que debía tener el tema de los Derechos Humanos en el proceso de transición democrática. En el caso de Vargas esto le permitió establecer relaciones y, posteriormente, incorporarse a los juristas que trabajaron en los dispositivos de Derechos Humanos que se implementaron en la transición democrática. Por ejemplo, en este espacio conoció a José Zalaquet ${ }^{18}$ quien tendría un rol fundamental en el diseño de la Comisión de Verdad y Justicia (Comisión Rettig) ${ }^{19}$. Como este programa funcionaba como un referente académico y de encuentro de las distintas organizaciones de Derechos Humanos en Chile, le permitió a Vargas trabajar como asesor de la "Vicaría de la Solidaridad" en el estudio de las posibles salidas a la problemática de los presos políticos de la dictadura que se deberían enfrentar una vez terminado el régimen autoritario. Esta experiencia se constituirá en un saber valorado en el primer gobierno de la

\footnotetext{
Entrevista realizada en noviembre de 2007.

Entrevista realizada en enero 2007.

18 José Zalaquett a partir de su itinerario forma parte de lo que Dezalay y Garth (2002) llaman un "notable cosmopolita del derecho", y es uno de los actores principales en la importación de la justicia transicional. Para conocer la trayectoria de Zalaquett ver Cuadros (2006: 210); Dezalay y Garth (2002: 234).

19 La Comisión Rettig fue un dispositivo, creado en el gobierno de Patricio Aylwin, que debía desarrollar la política de reconciliación nacional al término de la dictadura de Augusto Pinochet. Esta comisión debía construir un relato oficial de los crímenes políticos cometidos durante la dictadura entre el 11 de septiembre de 1973 y el 10 de marzo de 1990 y realizar la descripción de los crímenes más graves, a partir de lo cual se podría definir una reparación para las familias de estas víctimas (Cuadros, 2006: 209).
} 
Concertación y le da la posibilidad de ser asesor del entonces Ministro de Justicia Francisco Cumplido, quien tenía entre sus primeras tareas el hacerse cargo de la situación de los presos políticos.

De esta manera Vargas termina por convertirse en asesor directo del Ministro de Justicia Francisco Cumplido para el proceso parlamentario de introducción de las reformas del primer gobierno de la Concertación, y miembro de la Comisión asesora del Presidente Patricio Aylwin para el estudio de las reformas al poder judicial. Es así como Vargas y Riego, en este primer momento, pudieron incorporarse en el mundo de juristas próximos a la Concertación, lo cual les posibilitó acceder a recursos de académicos y políticos, a los que hasta entonces no tenían acceso.

En este punto de la trayectoria de ambos juristas, es importante considerar la figura de Jorge Correa Sutil, quien tuvo un rol importante en la construcción de iniciativas de modernización a la justicia en Chile. Éste, a fines de la década de 1970 fue secretario del Grupo de Estudios Constitucionales (Grupo de los 24) 20 . Esta instancia, que nutrió la agenda de reformas de la justicia del primer gobierno de la Concertación, agrupaba a políticos democratacristianos y prestigiados juristas que generaron un debate en torno a los planes de la dictadura para instaurar una nueva constitución y que reflexionaban acerca de la modernización de la justicia como parte de una estrategia de oposición a la dictadura. Los principales objetivos de esta agenda eran intervenir la estructura del poder judicial para brindarle una mayor autonomía e independencia interna, modernizar la gestión de los tribunales y mejorar el acceso a la justicia ${ }^{21}$.

Correa Sutil, a la vuelta de un postgrado en Yale en el año 1982 se incorporó como decano de la Facultad de Derecho de la Universidad Diego Portales (UDP), la que originalmente estaba orientada en la formación de abogados que pudieran desempeñarse en el mundo de los negocios. Correa Sutil, retomando la agenda del "Grupo de los 24", amplió el trabajo de esta facultad hacia los temas de Derechos Humanos, acciones de interés público y temas relacionados con el estudio y análisis de la modernización de la justicia ${ }^{22}$. Así la Facultad de Derecho de la UDP, bajo la dirección de Correa Sutil, incorporó a profesores que habían sido marginados o que presentaban un profundo malestar con las universidades tradicionales, además de un grupo de jueces que tenían una visión crítica del statu quo existente en el poder judicial. De esta manera la UDP permite un diálogo entre algunos jueces y el mundo de juristas críticos, estableciendo un espacio inicial de entendimiento y acercamiento. A su vez, los profesores incorporados a esta Facultad traen consigo a sus ayudantes, los cuales son juristas jóvenes que participan activamente de las actividades de la UDP, generando inclusive instancias

20 El “Grupo de los 24" fue creado el año 1978 (en plena dictadura), sobre el rol del grupo ver Puryear (1994:41).

${ }^{21}$ En concreto esos objetivos se traducían en: la creación de un Consejo Superior de la Magistratura; cambios en la composición y funcionamiento de la Corte Suprema; creación de la Academia Judicial; aumento de la transparencia y objetividad en la carrera funcionaria; creación de un Defensor del Pueblo; creación de un servicio de asistencia jurídica; creación de tribunales de proximidad; ampliación del arbitraje; y restablecimiento del Ministerio Público en primera instancia

22 Entrevista realizada en noviembre de 2007. 
propias de reflexión y discusión. Entre estos ayudantes se encontraba Cristián Riego, quien se incorpora como ayudante de Jorge Mera en derecho penal.

Paralelamente, entre 1990 y 1991 se pone en funcionamiento la "Comisión Rettig". Correa Sutil fue nombrado secretario ejecutivo de esta comisión y como tal tenía que seleccionar y dirigir los equipos de abogados que trabajarían en ella. Producto del consenso político que se pretendía construir alrededor de las conclusiones de esta comisión ${ }^{23}$, Correa Sutil debía seleccionar abogados que nunca hubieran defendido una causa de Derechos Humanos. Es así como éste, para constituir los equipos de trabajo, se apoyó principalmente en los juristas que trabajaban en la UDP. Entre los juristas que invita estaba Cristián Riego, quien, a su vez, le recomendó incorporar a Vargas a esta comisión. Es así como ambos juristas se incorporaron a trabajar en los dispositivos de justicia transicional creados por la Concertación (para un análisis crítico de estos dispositivos ver: Cuadros, 2003 y 2006).

En 1991, y de manera posterior a la "Comisión Rettig", por iniciativa de Correa Sutil se creó en la UDP el Departamento de Investigaciones Jurídicas, que posteriormente dio origen a su Centro de Investigaciones Jurídicas (CIJ). Este centro tenía el objetivo declarado de "apoyar el desarrollo y la ejecución de políticas públicas en el área del derecho y la justicia en el país"24. A estas alturas Riego, que ya poseía el rango de profesor en la UDP, se incorporó al CIJ, espacio que le permitió desarrollar una serie de estudios sobre el funcionamiento del sistema penal ${ }^{25}$.

Paralelamente, USAID ofreció un financiamiento a los juristas críticos y los jueces asociados al Instituto de Estudios Judiciales ${ }^{26}$ que utilizaban la UDP y la Corporación de Promoción Universitaria (CPU) ${ }^{27}$ como punto de encuentro y

23 Entrevista realizada en noviembre de 2007. En efecto, esta comisión estaba compuesta tanto por adherentes al régimen militar, por expertos y en particular por abogados que pertenecían o tenían una afinidad con la democracia cristiana y que al interior del mundo de los Derechos Humanos ocupan una posición de experto de gobierno a diferencia de los "militantes-expertos" de la causa de Derechos Humanos (Cuadros, 2006: 219).

24 Objetivo publicado en antiguo sitio web de la facultad de derecho de la UDP. http://www.udp.cl/derecho/centroinvestigaciones.html (sitio válido al 12/09/2006).

Según esta misma presentación este centro, para cumplir con sus objetivos, ejecutaba proyectos de investigación financiados con fondos internos y externos, realizaba actividades de extensión y desarrollaba asesorías y consultorías en Chile y el extranjero. Además en esta misma presentación se señalaba que el enfoque con que trabajaban excedía el análisis jurídico tradicional, y ponían el acento en el "funcionamiento concreto de las instituciones", a partir de análisis empíricos multidisciplinarios.

Hoy en día esta facultad organiza su actividad de investigación a partir de tres centros de investigación y dos programas de investigación. Al respecto ver http://www.udp.cl/derecho/investigacion.htm (última visita el 14/04/09).

25 Como veremos, estos estudios fueron utilizados en la creación de un consenso en torno a la necesidad de una reforma del sistema de enjuiciamiento criminal.

26 Instancia académica creada por jueces pertenecientes a la Asociación Nacional de Magistrados y que pertenecían a los sectores críticos al interior de esta asociación que eran liderados por Hernán Correa de la Cerda (Hilbink, 2007:162).

27 Esta corporación era una de las más antiguas ONGs chilenas, creada a fines de los años 60, que tradicionalmente trabajaba en el área de educación, desarrollo social y cooperación internacional, ejecutando diversos programas tanto con fondos nacionales como extranjeros (Urzúa, 2000: 124). Esta ONG estaba ligada al mundo democratacristiano. 
discusión. Este financiamiento estaba dirigido a trabajar en torno a estudios de reformas a la justicia y en capacitación judicial. USAID dirigió este financiamiento hacia la CPU, donde se crea un proyecto que tenía como áreas de trabajo la capacitación judicial, la administración de tribunales y la asistencia jurídica. Este proyecto retomaba los intereses del "Grupo de los 24", los que a su vez coincidían con la agenda de reformas a la justicia promovida por USAID que apuntaba al fortalecimiento institucional como apoyo a los procesos de democratización.

A partir de la experiencia de este primer proyecto en CPU, se obtuvo un segundo financiamiento de USAID, de 1991 a 1995, para ampliar la experiencia y conocimiento necesarios para promover las reformas del sector judicial. Así, para la ejecución de este proyecto, se creó el Centro de Estudios Jurídicos Judiciales de la CPU, donde Correa Sutil, que estaba a cargo del área de asistencia jurídica, propuso la incorporación de Vargas a cargo del área de administración de tribunales.

El trabajo y contactos que estableció Vargas en CPU fueron claves en la inserción de éste como consultor en el espacio internacional ${ }^{28}$. Así por ejemplo, fue invitado a participar en la preparación de la primera conferencia del BID sobre la justicia en San José de Costa Rica (Febrero 1993), donde se hace cargo del área de capacitación judicial y participa en la elaboración del informe de dicha conferencia. Así, ya establecido el vínculo con el exterior, Vargas comienza a participar en la escena latinoamericana asesorando al BID, al Banco Mundial y realizando evaluaciones de experiencias de transformación de la justicia en otros países ${ }^{29}$. Paralelo a esto, a fines de los 80 estos juristas habían creado un estudio de abogados independiente ${ }^{30}$, actividad que intentan llevar en paralelo a esta actividad académica pero que posteriormente será dejada de lado.

Como pudimos observar en esta sección, a partir de la búsqueda de espacios alternativos al dominante en el campo jurídico durante los últimos años de la dictadura, Riego y Vargas inician un proceso de formación y desarrollo profesional paralelo que los llevará a participar del espacio en que se generarán las iniciativas de reforma judicial asociadas a la transición democrática. Esto les permitirá entrar en relación con el mundo de los juristas que importan y generan los dispositivos de Derechos Humanos y de transformación de la justicia del primer gobierno de la Concertación. En este sentido estas trayectorias encuentran sus condiciones de posibilidad en un contexto específico del campo jurídico y político en Chile marcado por la transición democrática.

Finalmente, a partir de su trayectoria inicial, observamos cómo ambos juristas se insertaron en espacios institucionales desde los cuales, tal como veremos en la próxima sección, en la primera mitad de la década de 1990, podrán llevar una estrategia para la promoción de la RPP, movilizando una serie de recursos de los cuales hasta ese entonces ni Vargas ni Riego tenían acceso.

28 Esta actividad se establece a través de los contactos del Director de CPU con Luciano Tomassini, quien era asesor de Enrique Iglesias, presidente del BID (entrevista realizada en enero 2007).

29 Entrevista realizada en enero de 2007.

30 En este estudio trabajaron Cristián Riego, Juan Enrique Vargas y Felipe González. 
La reforma procesal penal en Chile: nuevos agentes, sus trayectorias...

\section{Legitimidad técnica y política de la reforma. La construcción de consensos y de una nueva expertise}

En esta sección veremos cómo, considerando la estructura del campo jurídico y político, Vargas y Riego generan una estrategia de construcción de consensos en torno a la idea de la RPP, dotando a esta propuesta de legitimidad técnica y política. En segundo lugar, veremos cómo a partir de esta estrategia estos agentes construyen un capital jurídico diferente al tradicional, a partir de la importación de ideas del exterior y de la incorporación de ideas de disciplinas distintas al derecho. Es decir, veremos cómo a partir de estas trayectorias y estrategia se constituye una expertise específica.

A principios de los años 1990, Riego y Vargas, junto a dos profesores de derecho penal ya mencionados en este artículo, Jorge Mera y Juan Bustos ${ }^{31}$, crearon una instancia de encuentro llamada la Asociación de Política Criminal. Para brindarle peso institucional a esta asociación, estos juristas utilizaron el alero de la Facultad de Derecho de la UDP. Desde esta asociación comenzaron a plantear las primeras ideas en torno al cambio del sistema de justicia criminal y convocaron a otros juristas interesados en el tema a participar de esta asociación como espacio de discusión. La presencia de figuras con prestigio como Juan Bustos les brindó la posibilidad de tener una tribuna al interior de la comunidad jurídica, a partir de la legitimidad y prestigio que este tipo de personalidades poseían.

Aunque este grupo tuvo una corta existencia, les permitió comenzar a construir las primeras ideas y discursos en torno a una posible reforma del proceso penal. Estas ideas quedaron plasmadas en un manifiesto que esta asociación publicó, y en el cual se planteaban los principios básicos de un proceso penal moderno, propio de una sociedad democrática, el cual debía asegurar el respeto de las garantías de los individuos y, a la vez, ser eficiente en la persecución de su objetivo (Asociación de Política Criminal, 1991:7-12; Valdivieso y Vargas, 2003:204). Ya a esta altura Vargas y Riego habían abandonado casi por completo el ejercicio liberal de la profesión, centrando su actividad en la labor académica desde el proyecto de la CPU y la UDP respectivamente.

Desde estos espacios, ambos agentes comienzan con una estrategia de realización de estudios y seminarios ${ }^{32}$, que en el caso del CIJ contaron, en su mayoría, con el financiamiento de Fundación Ford. En estos seminarios se presentaban los estudios críticos que se habían realizado sobre el funcionamiento del sistema penal. Esto les permitió avanzar en la sensibilización de la comunidad jurídica sobre la necesidad de la reforma del sistema de enjuiciamiento criminal y, a la

31 Destacado penalista que venía del exilio. Este jurista disponía de un gran prestigio académico dada su condición de doctorado en Alemania y de haber sido académico de la Universidad Pompeu Fabra de Barcelona. Los primeros años de su llegada a Chile se dedicó al trabajo académico, para reconvertirse posteriormente a la Política. Este jurista terminó su carrera como presidente de la Cámara de Diputados, falleciendo antes de terminar con su periodo en tal función (2008).

32 Entre estos estudios destacan los realizados por Cristián Riego (1994) y María Angélica Jiménez (1994) en el Centro de Investigaciones Jurídicas (Urzúa, 2000: 138). 
vez, les permitió establecer las redes que les utilizaron posteriormente para llevar a cabo tal reforma.

Esta estrategia también fue importante, ya que en esos momentos el derecho procesal penal no estaba en el centro de las preocupaciones del mundo jurídico ${ }^{33}$ y las reflexiones académicas sobre el funcionamiento de la justicia criminal no eran muy abundantes. Además los juristas que promovían y participaban de la primera agenda de reformas de la Concertación no estaban interesados en el funcionamiento del sistema penal ${ }^{34}$. Esto hace que todos los estudios y seminarios que Riego y Vargas realizaban o promovían los fueran posicionando, dentro del campo jurídico nacional, como expertos en el área dada la ausencia de reflexión ya mencionada sobre el tema ${ }^{35}$.

Como parte de esta estrategia, en 1992 la UDP y la CPU realizaron un seminario en conjunto con la Universidad Católica de Valparaíso, sobre el impacto de la oralidad de los procesos en las reformas de la justicia en América Latina ${ }^{36}$. Este seminario es considerado como una actividad clave en el impulso y creación de un consenso acerca de la necesidad de una reforma del sistema de enjuiciamiento criminal (Urzúa, 2000: 142; Valdivieso y Vargas, 2003: 204; Duce, 2004: 204). En este seminario participaron los juristas argentinos Julio Maier y Alberto Binder, quienes eran los primeros que, a nivel regional, promovían una reforma en el sistema procesal penal. Ellos promovían un modelo de procedimiento penal inspirado en el Código Procesal Penal Modelo para Ibero América ${ }^{37}$, del cual Maier fue uno de sus redactores y que recoge las propuestas del Proyecto de Código Procesal Penal de 1986 propuesto por el gobierno de Raúl Alfonsín en Argentina, del cual Maier también fue su redactor, tarea en la que fue asistido por Alberto Binder. El proyecto del año 1986, y por ende el Código Modelo, tiene como fuentes principales la Ordenanza Procesal Alemana y el Código de 1939 de la Provincia de Córdoba, el cual, a su vez, tenía como fuentes los códigos italianos de 1913 y $1930^{38}$.

33 Entrevistas realizadas en enero 2007 y noviembre 2007.

34 En este sentido es importante constatar que la justicia criminal ha sido un área subordinada en el mundo jurídico tradicional, siendo considerado el derecho procesal penal como un sub-área del derecho procesal en los programas de enseñanza universitaria. Además, como Dezalay y Garth (2002) lo señalan, las elites en el Chile de transición se interesan principalmente en reformas asociadas a los objetivos de la transición democrática, como eran los dispositivos de justicia transicional y las propuestas recogidas de las proposiciones del "Grupo de los 24".

35 Esta ausencia de reflexión en el área es constatada por todos los entrevistados que participaron en la génesis de la reforma procesal penal. Así entre estos entrevistados reconocen que a partir de su interés y estudios en el área el volverse un experto sobre el tema en campo jurídico nacional no era algo "imposible". Entrevistas realizadas en enero y noviembre de 2007.

36 Los contenidos de este seminario están publicados en Maier y Tavolari (1993).

37 Este código modelo es una iniciativa del Instituto Iberoamericano de Derecho Procesal, que existe desde fines de los años 50 en Uruguay y que agrupa a juristas de los países iberoamericanos. Desde 1978 este instituto trabajaba en un proyecto de un nuevo código procesal penal y civil, con el objetivo de orientar las reformas de los países de la región, en vistas de una futura integración regional. Es a partir de varios congresos realizados que este código modelo sufre modificaciones para terminar en su versión definitiva en 1988 (Urzúa, 2000:142).

38 Respecto de las fuentes de estos proyectos de código, ver Langer, 2007: 634-646. 
La reforma procesal penal en Chile: nuevos agentes, sus trayectorias...

Como ya mencionamos, Maier y Binder habían tenido un importante rol en el proyecto de reforma del procedimiento penal de 1986, a partir de lo cual fueron invitados a colaborar en los procesos de reforma en Guatemala y Costa Rica. En particular estos juristas argentinos, en conjunto con juristas locales, frente a quienes estaban bastante legitimados, negocian con USAID la inclusión de la reforma procesal penal en la agenda de reformas a la justicia que esta agencia deseaba instalar en ambos países como parte de la segunda ola de la "Rule of Law" en América Latina (Langer, 2007: 649-651).

A partir de esta experiencia, y alentados particularmente por Alberto Binder ${ }^{39}$, Riego y Vargas, convocaron a través de CPU, en agosto de 1993, a una instancia llamada "Foro por la Oralidad de los Procesos". Ésta era una instancia de discusión que incorporaba a representantes de los diversos intereses al interior del mundo jurídico y de los principales sectores políticos, para reflexionar y crear un consenso sobre la necesidad de una posible reforma del sistema de enjuiciamiento criminal chileno (Urzúa, 2000:146). Al mismo tiempo, Vargas negoció con USAID la incorporación de un área de justicia penal en el proyecto que esta agencia financiaba en la CPU, la cual acepta y extiende el financiamiento al proyecto de la CPU hasta 1996 (éste es un aspecto importante cuyas condiciones de posibilidad se analizarán en la próxima sección).

A esta altura del trabajo, Vargas y Riego establecieron vínculos con la Fundación Paz Ciudadana (FPC). Esta institución trabaja los temas de seguridad y está ligada a los sectores de derecha del país, no obstante en su directorio participan miembros de la Concertación ${ }^{40}$.

Una característica importante del trabajo de FPC es que cuenta con un gran eco en los medios de comunicación, lo que le ha permitido influir en la agenda pública, posicionando el tema de la seguridad ciudadana. Así, en 1994, se creó una alianza de trabajo entre CPU y FPC. Esta alianza aparecía como estratégica, pues permitía contar con un cierto nivel de representatividad de las diferentes posiciones políticas entre quienes promovían la reforma, puesto que la inclusión de FPC aseguraba tener una representación de sectores cercanos a la derecha política en el país (Urzúa, 2000: 148).

En este escenario, en el año 1994 los agentes involucrados en la reforma crean, a partir del "Foro por la Oralidad de los Procesos", una instancia de trabajo cuya misión es realizar una propuesta concreta de reforma del proceso penal chileno, la que se llama el "Foro por la Reforma Procesal Penal" (Urzúa, 2000:148) ${ }^{41}$. Así, en este Foro, la multiplicidad de actores aseguraba tener desde representantes de la nueva generación de juristas hasta miembros de la Corte Suprema, lo que

39 Entrevistas realizadas en enero de 2007 y agosto de 2008.

40 La Fundación Paz Ciudadana fue creada por Agustín Edwards, propietario de la empresa editorial "El Mercurio", a partir de una reacción de éste frente al secuestro de su hijo por un grupo de extrema izquierda chileno. Desde su creación en 1992 trabaja sobre temas de seguridad y administración del sistema de justicia.

41 De ahora en adelante "Foro". 
a ojos de los sectores tradicionales le entregaba la "sabiduría y experiencia" a un proceso que tenía como rasgo diferenciador el recambio generacional (Vargas 1998: 102).

La creación de este Foro, como estrategia para generar consensos en torno a una propuesta concreta de reforma, fue fruto del aprendizaje de las dificultades que enfrentaron los proyectos de reforma de la justicia iniciados durante el primer gobierno de la Concertación (Patricio Aylwin, 1990-1994). Se asumía que si estos proyectos no habían obtenido los resultados esperados ${ }^{42}$ ello era debido a la oposición de la derecha política y a la resistencia corporativa del poder judicial que éstos generaron. Esta resistencia fue entendida como consecuencia de la exclusión que se había hecho de los principales actores judiciales y del tipo de argumentos sobre los cuales se apoyaban estas reformas. Estos argumentos provenían de un contexto de esclarecimiento de las violaciones de los Derechos Humanos durante la dictadura y una crítica al poder judicial por su falta de compromiso en esclarecer estas situaciones (Urzúa, 2000: 133). Así estas reformas, tal como había ocurrido con otros intentos de reforma de la justicia en la región, encontraron resistencias corporativas y políticas ${ }^{43}$.

Entre las instancias de trabajo del Foro se constituye un equipo de dirección y un equipo técnico. El equipo de dirección estaba formado por Vargas, Riego y la Gerenta de FPC $M^{a}$ Pía Guzmán ${ }^{44}$. En el equipo técnico participan Riego, Mauricio Duce, su ayudante, y dos jóvenes juristas: Jorge Bofill ${ }^{45}$ jurista doctorado en derecho procesal penal en Alemania (Universidad de Friburgo); y María Inés Horvitz $^{46}$ doctorada en derecho penal en España (Universidad Pompeu Fabra) y con estudios de derecho penal en Alemania. Este equipo técnico, que contaba con la asesoría de los juristas argentinos Julio Maier y Alberto Binder, era el encargado de producir las propuestas técnicas que eran sometidas a la discusión del Foro (Duce, 2004: 208-209).

En definitiva los agentes que promueven la RPP elaboran una estrategia de incorporación de representantes de diversos sectores del mundo jurídico y político, que toma en cuenta la estructura de poder del campo jurídico y sus nexos con el campo político en el país. Así por ejemplo, utilizando los análisis de Vauchez y Willemez (2007), la instancia del foro se constituye como un espacio de discusión relativamente variado en el que se "hace emerger el sentido común reforma-

42 De hecho estos proyectos sólo fueron aprobados, de manera parcial, en el segundo gobierno de la Concertación (Eduardo Frei Ruiz-Tagle, 1994-2000).

43 Respecto a los obstáculos que enfrentan los procesos de cambio a la justicia. ver Pásara (2002).

44 Abogada y diputada por el Partido de derecha "Renovación Nacional" en dos períodos parlamentarios consecutivos (1998-2002 y 2002-2006).

45 Este joven jurista provenía de provincia. A partir de un artículo que escribe es invitado por Riego a participar del equipo técnico. Como señala el mismo Bofill, en esos tiempos eran pocos los doctorados y personas que se interesaran por el derecho procesal penal (entrevista noviembre 2007).

46 Esta jurista fue compañera de universidad de Vargas y Riego. Formó parte del grupo de estudiantes que participaba de los cursos de la AHC. También participó en la Asociación de Política Criminal, invitada por Juan Bustos, quien había sido su director de doctorado (entrevista noviembre 2007). 
dor" ${ }^{\prime 2}$, y en el cual se neutralizan los intereses particulares, dado su carácter de "lugar neutro" 48 donde se reúnen distintos grupos y se mezclan sus concepciones de reforma.

En este sentido, nos encontramos con una nueva generación de juristas que promueve el cambio en el mundo jurídico chileno, cuyo elemento característico es la capacidad de establecer alianzas con instituciones y agentes que participaban tanto del legado de la derecha como de los grupos cercanos a la Concertación (Dezalay y Garth, 1998:83). De esta manera esta nueva generación promueve una transformación en el área de la justicia, creando instancias que entregan una legitimidad técnica y política a sus propuestas.

A su vez, estos juristas, en el proceso de construcción de propuestas para la reforma, movilizan una expertise o un capital diferente al del mundo del derecho procesal tradicional chileno, ligado a una cultura inquisitoria escrita. A esta altura estos actores están en condiciones de importar un saber proveniente del derecho europeo, en particular del alemán, contenidos en el Código Modelo para Iberoamérica a partir de la influencia de Maier y Binder y por la experiencia de Bofill y Horvitz. Además Vargas y Riego aportan un enfoque de modernización de políticas públicas, dado por los espacios institucionales desde los cuales trabajan y por su propia formación. En este último punto también es importante el aporte de Binder, quien también tiene un enfoque de políticas públicas en la implementación de la reforma a partir de su experiencia en el proceso argentino, donde el diseño de implementación fue más allá del solo aspecto normativo y fue concebido con un enfoque de políticas públicas ${ }^{49}$.

En la siguiente sección veremos cómo la estrategia de legitimación técnica y política, que los agentes de la reforma llevan a cabo, les permite hacer competir la reforma procesal penal con la agenda de reformas dominante en esos momentos.

\section{La reforma procesal penal y la Primera Agenda de reformas a la justicia en democracia}

Como ya señalamos, en los momentos que Riego y Vargas comienzan a trabajar en la RPP, tanto la agenda de reforma a la justicia dominante en el primer Gobierno de la Concertación como el proyecto de CPU financiado por USAID, no consideraban esta reforma.

47 Me refiero a la misma noción de Topalov (1999) y que Vauchez y Willemez (2007) utilizan para el análisis de las reformas a la justicia en Francia. "Sentido común reformador" entendido como un sentido o un leguaje compartido, como definición común de problemas y de un horizonte de salida. Eso sí, este sentido compartido no implica un consenso sobre las modalidades concretas de la acción, ni menos sobre los fines últimos (Topalov, 1999: 44).

48 Vauchez y Willemez (2007) en su análisis del espacio de las reformas de la justicia en Francia, aplican los conceptos de "lugar neutro" (Bourdieu y Boltanski, 1976) y de "sentido común reformador" (Topalov, 1999).

49 Entrevista realizada en agosto 2008. 
Por otra parte, en el caso de USAID, desde mediados de los años 1980, la estrategia de reforma judicial se inscribía en una política exterior del Departamento de Estado del gobierno de EE.UU. de apoyo a las transiciones democráticas. Ésta se vinculaba a la modernización, fortalecimiento institucional y capacitación de tribunales (segunda ola de programas de Rule of Law), cuyos resultados, no siempre fueron tan exitosos (Dezalay y Garth, 2002. 373).

La base de apoyo u oposición que éstas reformas encontraban en los espacios locales determinaba sus posibilidades de éxito, así como la orientación que tomaba la agenda de reforma judicial promovida por esta agencia (Faúndez y Pásara, 2007:5). Así por ejemplo, en los casos en que había agentes locales interesados en procesos de reforma judicial, éstos eran viables y sus contenidos eran el resultado de una interacción y muchas veces negociación entre esta agencia y los agentes locales ${ }^{50}$.

En el caso de Chile las dificultades y los limitados avances que tuvieron estas agendas, facilitaron que los promotores de la RPP pudieran posicionar esta reforma frente a la agenda promovida por USAID en el proyecto CPU y a aquella que se promovía en la esfera gubernamental.

Así, por ejemplo, el proyecto CPU en este periodo fue sometido a una evaluación externa encargada por USAID. Dicha evaluación fue negativa respecto de la marcha y los resultados de este proyecto, lo cual no fue compartido por los responsables locales del proyecto ya que consideraban que ésta no daba cuenta adecuadamente de los logros obtenidos hasta el momento. Frente a esto los responsables locales del proyecto, entre los que participaba Vargas, elaboraron un informe dirigido a USAID en Washington. Dicho informe sirvió para contrarrestar la evaluación externa del proyecto y a la vez fortaleció los puntos de vista y posición de los responsables locales de proyecto CPU frente a esta agencia ${ }^{51}$.

Si bien la situación descrita fue sorteada exitosamente por el equipo del proyecto $\mathrm{CPU}$, ésta generó un proceso de reflexión interna en el equipo en el que se reconoció que si bien existían algunos avances, éstos no tenían la profundidad deseada. Todo esto generó un ambiente propicio para que, al interior de la CPU, se comenzara a redefinir los lineamientos y desarrollo del proyecto.

Lo anterior, sumado al consenso que se generó en torno a la idea de una reforma del sistema de enjuiciamiento criminal, le permitió a Vargas promover la idea de incluir un área de reforma a la justicia penal en el proyecto CPU. Es así como en 1993, producto de una negociación entre USAID y los responsables del proyecto, se incluyó un área de reforma a la justicia criminal en CPU.

Respecto de la agenda gubernamental de reformas a la justicia, como veremos a continuación, fueron las dificultades que esta agenda enfrentó junto a la legiti-

50 Tal es el caso de la reforma procesal penal en Guatemala, a la que hicimos referencia a partir del rol de Binder y Maier en Centroamérica.

51 Es así como posteriormente a esto desde USAID se nombró a un nuevo encargado como contraparte del equipo directivo del proyecto de la CPU. Éste le entregó un mayor marco de maniobra al equipo de CPU respecto de la orientación de las acciones emprendidas en el marco del proyecto (entrevista realizada en noviembre 2007). 
midad que poseía la RPP las que permitieron posicionar a esta última en la discusión de reformas a la justicia. Como ya habíamos mencionado, al fin del primer gobierno de la Concertación los proyectos de reforma de la justicia no tuvieron los resultados esperados debido a la oposición política de la derecha y la oposición corporativa del poder judicial (Urzúa, 2000). Por otra parte la participación de distintos grupos y el consenso técnico y político construido alrededor de las propuestas elaboradas por el Foro de la RPP, fueron los factores que posibilitaron incluir en el programa del segundo gobierno de la Concertación una alusión general a la necesidad de transformar el sistema de enjuiciamiento criminal. A esto se le sumó la participación de miembros de la CPU y del FPC, en la comisión política que elaboró el programa de gobierno de Eduardo Frei Ruiz-Tagle (Urzúa, 2000:150).

Ahora bien, el programa de Frei realizaba alusiones generales a la necesidad del cambio del sistema procesal penal, pero la preocupación principal de su gobierno en el área de justicia era tratar de terminar de tramitar las reformas que habían quedado pendientes del gobierno de Patricio Aylwin. Además en la elite gubernamental, formada por juristas tradicionales, por economistas y cientistas sociales, no existía un interés profundo en cambiar el rol de los tribunales en la esfera estatal (Dezalay y Garth, 2002:349), sino que éste se reducía a los objetivos políticos de la transición.

No obstante lo anterior, la RPP ofrecía, a lo menos a nivel teórico, solucionar dos problemas de la justicia penal que para los países en transición democrática parecían ser importantes. Por un lado, la reforma ofrecía asegurar el respeto de las garantías básicas de las personas. Por otro lado, ofrecía aumentar la eficiencia del sistema penal para hacer frente a los problemas de seguridad que comenzaban a aparecer en la agenda pública (Vargas, 1997:9), y del cual la derecha realizaba un uso político contra la coalición de gobierno.

Además, este proyecto poseía una perspectiva modernizadora (Vargas, 1998), acorde con el discurso de la transformación del Estado que está presente en la transición democrática, lo que contribuía a disminuir las diferencias políticas en torno a este tipo de proyecto, circunscribiendo la discusión a una lógica de eficiencia de la justicia ${ }^{52}$. Esto facilitaba en alguna medida la aceptación de esta reforma por parte de quienes tenían a su cargo la construcción del Estado (Dezalay y Garth, 1998:91). Estos elementos facilitaron el acercamiento entre el equipo de dirección del Foro con el Ministerio de Justicia, con miras a convencer a dicho ministerio de tomar como propia la iniciativa de reforma.

Otro aspecto que facilitó el acercamiento entre los promotores de la reforma y el Ministerio de Justicia fue el rol que cumplió un asesor de Soledad Alvear, Ministra de la Justicia y militante democratacristiana. Este asesor es Carlos Peña -académico de la UDP, investigador del CIJ, ex decano de la Facultad de Derecho de la UDP y actual Rector de la misma-, quien, viniendo del mismo espacio aca-

52 Para un análisis del rol que cumple la tecnificación en la adopción de proyectos de reforma, ver Virgour (2006). 
démico que Riego ${ }^{53}$, le recomendó a Soledad Alvear incorporar esta iniciativa a la agenda ministerial, contrapesando el rol de otros asesores que no estaban convencidos de la conveniencia de esto ${ }^{54}$. Es en este punto que se produce un cambio fundamental en la agenda de justicia que venía trabajando la Concertación.

Como parte de los asesores de la Ministra de Justicia, Correa Sutil participó en la discusión de las agendas. Éste, como ya vimos, formaba parte de los juristas que nutrieron la primera agenda de reforma judicial. Es interesante ver cómo Correa Sutil señala que no se percata de la manera que la RPP adquiere fuerza, puesto que era un tema que le importaba "sólo a los penalistas", pero que de repente irrumpe entregando respuestas a problemas de la transición democrática (respeto de los derechos fundamentales y la seguridad ciudadana), "con un alto nivel técnico" ${ }^{\prime 5}$. Así, en 1994, se elaboró un acuerdo de trabajo para incorporar la RPP como iniciativa gubernamental. Este acuerdo contemplaba la participación en conjunto del Ministerio de Justicia, de CPU y de FPC. Posteriormente, en 1995, la Ministra Soledad Alvear presentó el proyecto a la comunidad jurídica nacional y en junio del mismo año el presidente Frei lo presentó al Congreso para su tramitación (Duce, 2004: 19 y 206).

En definitiva podemos ver cómo existe una continuidad y ruptura con la agenda tomada por el primer gobierno de la Concertación y USAID en esos momentos. Esto podría explicarse por la posición intermedia que ocupan los juristas que promueven la RPP. Así Vargas y Riego, si bien se insertan en el espacio de los juristas que diseñan la reforma judicial en función de los objetivos de la transición democrática, no pertenecen originalmente a este mundo de "notables" del derecho que construyen esta agenda de reforma judicial, sino que se suman a las iniciativas que estos últimos tenían medianamente definidas. De esta manera nos encontramos con dos juristas que, inicialmente, se insertan a trabajar en el espacio de la reforma judicial dominado por la agenda de la transición, pero que posteriormente movilizarán un saber y objeto de interés que competirá con dicha agenda, constituyéndose en lo que Bourdieu (1989) identifica como los partidarios del cambio al interior del campo jurídico ${ }^{56}$.

53 Peña, al igual que Riego, formaba parte del grupo de jóvenes juristas que se incorporan como ayudantes a la Facultad de Derecho de la UDP cuando Jorge Correa Sutil era decano y que participan activamente en la UDP.

54 Entrevistas realizadas en enero y noviembre 2007.

55 Entrevista realizada en noviembre 2007.

56 "los partidarios del cambio se sitúan del lado de la ciencia, de la lectura contextualizada históricamente (...) y de la atención a la jurisprudencia, es decir, a los nuevos problemas y formas de derecho que estos problemas exigen (derecho comercial, derecho del trabajo, derecho penal)" (Bourdieu, 1989:18) (Traducción libre). 
La reforma procesal penal en Chile: nuevos agentes, sus trayectorias...

\section{La tramitación parlamentaria. Movilización de capital político y una segunda etapa en la importación de ideas}

En esta parte se analizará, en primer lugar, cómo en la discusión parlamentaria de la RPP entra en juego la variable política, lo que hace que los promotores de la reforma movilicen un capital político favorable a la reforma. Y en segundo lugar veremos cómo, en esta etapa, se produce una segunda importación de ideas con la incorporación de elementos del sistema procesal penal anglosajón, que se relaciona con la estrategia de internacionalización de un par de miembros del equipo que asesora al gobierno.

Si bien inicialmente existía un consenso relativo respecto de la RPP, al momento de la tramitación parlamentaria volvieron a aparecer ciertas resistencias, sobre todo de parte de la comunidad jurídica (Duce, 2004:226). También se presentó una oposición en ciertos temas sensibles para la clase política como la autonomía del Ministerio Público (Vargas, 1998:116).

En tal contexto resulta fundamental que la ministra Soledad Alvear haya tomado un rol activo en los debates parlamentarios (Valdivieso y Vargas, 2003:206). Además es importante el apoyo mediático que requería este tipo de reforma, que pudo asegurarse con la participación de FPC y la legitimidad técnica de los miembros del equipo técnico del Foro, quienes participaron posteriormente como asesores durante la tramitación parlamentaria ${ }^{57}$. Así vemos cómo estos reformadores se articulan con el campo político para obtener la aprobación de las reformas que ellos proponen.

El proyecto que fue presentado al parlamento es el reflejo de la expertise que está asociada a la trayectoria de los juristas que promueven el proceso de reforma. Así se tiene, por un lado, que el proyecto de reforma que se envía al parlamento recoge la influencia del Código Procesal Penal Modelo para Iberoamérica y en consecuencia elementos del derecho europeo. Esto se ve favorecido por el aporte de los ya mencionados Horvitz y Bofill, que rescatan la tradición del derecho alemán, y por los aportes posteriores de Raúl Tavolari ${ }^{58}$, quien es incluido en el equipo que redacta el proyecto de código penal una vez que se firmó el convenio de trabajo en conjunto con el Ministerio de Justicia. Por otra parte, este proyecto posee un enfoque que apunta a la modernización de la gestión de la administración de justicia. Este enfoque es acorde con los perfiles de los agentes de la reforma ${ }^{59}$

57 A medida que el proceso de reforma avanzaba, se iban creando instancias de trabajo gubernamentales y los actores que estuvieron promoviéndola pasaron a cumplir roles asesores.

58 Este jurista provenía del mundo tradicional, asociado al derecho procesal; era un reconocido profesor de derecho universitario que pertenecía a una distinguida familia de juristas de provincia. Pero además, tenía la particularidad de ser uno de los pocos de su generación que estableció nexos con el exterior, en particular con la comunidad jurídica asociada al Instituto Iberoamericano de Derecho Procesal, institución desde donde se redacta el código modelo que Binder y Maier promovían (entrevista realizada en noviembre 2007).

59 En este sentido es importante recordar la formación específica que había adquirido Riego en el PET, y que por otro lado en este periodo Juan Enrique Vargas realiza un magister en gestión y políticas públicas en el Departamento de Ingeniería Industrial de la Universidad de Chile (título que obtiene en 1997). 
y las instituciones en las que se desempeñan, las que son espacios que potencian un enfoque de modernización de políticas públicas aplicado al análisis del funcionamiento de la justicia, como lo es el caso del programa de CPU y el CIJ, lo que se suma al aporte que en esta misma área realiza la $\mathrm{FPC}^{60}$. Ahora bien, como adelantamos, una vez que avanza la tramitación parlamentaria, el proyecto inicial sufre modificaciones que le agregan elementos propios del modelo anglosajón ${ }^{61}$.

En primer lugar, esto se debe a que el proyecto que se presenta es una apuesta por parte de los redactores, puesto que era la primera vez que cada uno de ellos participaba en la redacción de un código y, para ellos mismos, sus propuestas tenían un carácter general de lo que este código debía ser ${ }^{62}$. En este sentido, para cada uno de los juristas del equipo que lo redactó este código se iba perfeccionando o, más bien, ellos iban teniendo certezas sobre él a medida que avanzaban la discusión parlamentaria y el análisis del proyecto.

En segundo lugar, esto se debe a contribuciones realizadas por parte del equipo de juristas que trabajan con Riego y Vargas, quienes tienen la oportunidad de trabajar con el Ministerio de Justicia en el seguimiento legislativo del proyecto. Estos aportes coinciden con que una parte de este equipo comienza a realizar estudios en Estados Unidos e incorporan elementos del modelo anglosajón de enjuiciamiento criminal en la asesoría que prestan en la tramitación parlamentaria. Fundamentalmente es el aporte que realizan Mauricio Duce ${ }^{63}$ y Andrés Baytelman ${ }^{64}$.

Estos dos últimos participan el año 1997 en un curso de metodologías de litigación organizado por el NITA (National Institute of Trial Advocacy). Esto a partir de contactos que anteriormente había establecido Baytelman en una pasantía patrocinada por la Universidad de Georgetown en una fiscalía del Bronx. Ambos juristas importan y traducen esta metodología, realizando un manual y talleres en la UDP. A partir de esto, el equipo encabezado por Vargas y Riego incorpora una parte de alegato en la instancia de juicio final parecida a la del sistema norteamericano. Además esta importación se ve facilitada por estudios de master en derecho que realizan Baytelman en la Universidad de Columbia, Cristián Riego en la Universidad de Wisconsin y Mauricio Duce en la Universidad de Stanford, lo que les permite tener una mayor cercanía y conocimiento del derecho norteamericano.

${ }^{60}$ FPC también aportó sus puntos de vista respecto de los criterios de penas y cálculos de costos del nuevo sistema de enjuiciamiento criminal.

61 Entrevistas realizadas en enero y noviembre de 2007.

62 Entrevistas realizadas en noviembre de 2007 a todos los miembros del equipo técnico que redactó el proyecto de código.

63 Éste participa inicialmente en la génesis de la reforma como ayudante de Cristián Riego. Posteriormente se convierte en un agente importante, trabajando como secretario ejecutivo del Equipo Técnico del Foro por la Reforma Procesal Penal, participando en el equipo que asesora al gobierno y al parlamento durante la tramitación parlamentaria. Todo esto acompañado de un trabajo académico de divulgación y promoción de la reforma con numerosas publicaciones (entrevista realizada en noviembre de 2007).

64 Este actor será posteriormente Fiscal de una unidad de investigación encargada de robos en el centro de la ciudad de Santiago, que utiliza estrategias consideradas innovadoras, por lo cual su actividad será de interés de los medios de comunicación. Finalmente este actor es nombrado a mediados el año 2007 como gerente de la Fundación Paz Ciudadana, cargo que ocupa hasta enero de 2009. 
La reforma procesal penal en Chile: nuevos agentes, sus trayectorias...

Así, finalmente, el Código Procesal Penal Chileno recoge ideas provenientes de Latinoamérica, como son aquellas provenientes del "Código Procesal Penal Modelo para Ibero América", del derecho europeo continental, y en particular del modelo alemán, así como elementos del sistema anglosajón. De esta manera este código es una traducción ${ }^{65}$ de ideas importadas desde el exterior adecuándolas a la realidad de Chile desde una perspectiva que pone énfasis en la modernización de las políticas públicas en justicia

Esta importación de ideas e inversión en la escena regional y en el exterior facilita la promoción de los cambios. En este sentido, la importación de ideas es una herramienta que otorga legitimidad a los agentes de la reforma, que les permite posicionarse mejor en el espacio jurídico y político y, de esta manera, promover una expertise específica de Estado ${ }^{66}$ que es la RPP.

Otro aspecto que resulta fundamental en este proceso es la estrategia interna para generar consensos y apoyos políticos necesarios para llevar a cabo esta reforma, que tiene en consideración la estructura de poder del campo político. Así se destaca la alianza de trabajo establecida con FPC, que permite contar con el apoyo de la derecha. Por otro lado aparece importante el rol de Soledad Alvear, Ministra de Justicia en ese entonces, quien defiende esta reforma, lo cual termina por fortalecer su posición al interior de su partido y al interior de la coalición de gobierno. En efecto, esta reforma aparece como uno de los grandes logros de los gobiernos de la Concertación en el área de la justicia, constituyéndose en una fuente de capital político. En este sentido, es importante tener en consideración que este proceso de reforma se inserta, a su vez, en la reproducción del poder de Estado en Chile (al respecto ver Dezalay y Garth, 1998).

\section{Los gestores de la reforma: emprendedores simbólicos en el campo jurídico nacional y el espacio regional de reformas a la justicia}

En esta sección veremos cómo la RPP permitió a los juristas que participaron en la gestación de estos cambios posicionarse tanto a nivel nacional como en el ámbito internacional de circulación de ideas y, en particular, a la red latinoamericana de juristas que trabajan en torno a la política judicial y las reformas en la región ${ }^{67}$. Veremos cómo en este posicionamiento estos juristas utilizan el capital y expertise adquiridas en este proceso para mantener esta posición obtenida como resultado de la RPP. Éstos se convertirán en lo que Dezalay y Garth (2002) identifican

Sobre el concepto de traducción ver Langer (2004).

66 En América Latina los procesos de importación simbólica han sido una herramienta importante en la competición por la constitución de un saber de estado y el campo de poder de Estado (ver Dezalay y Garth, 2002).

67 Respecto del espacio regional de circulación de ideas, ver Langer (2007). 
como "emprendedores" que se especializan en el mercado de promoción de reformas institucionales, que corresponden a una categoría híbrida de académicos convertidos en emprendedores simbólicos como consultores. Esta actividad la desarrollan tanto en el espacio nacional como internacional.

Así, a nivel internacional, por iniciativa del Gobierno de Estados Unidos, y en particular de algunos miembros de USAID y del Departamento de Estado, se creó el Centro de Estudios de la Justicia en las Américas (CEJA), como un centro que funciona bajo la tutela de la OEA (Organización de Estados Americanos) (Langer, 2007:655). La sede de CEJA se instaló en Santiago de Chile, gracias a que la experiencia de la reforma chilena era vista de manera positiva por Estados Unidos y también por la promoción que en esta dirección realizó Soledad Alvear. Establecido CEJA, en el año 2000, Vargas fue nombrado su Director Ejecutivo, en donde jugó un rol importante el apoyo brindado por USAID a su postulación ${ }^{68}$. Una vez nombrado éste se incorporan Riego ${ }^{69}$ y Duce $^{70}$ en el equipo principal de este centro.

La labor que realizan estos juristas desde CEJA es el seguimiento de los procesos de reforma en otros países de la región, asesorías a los gobiernos, seminarios y publicaciones sobre el funcionamiento de los sistemas de justicia y las reformas implementadas en la región. CEJA se constituye en el lugar que a Riego, Vargas y Duce les permite insertarse en el espacio regional de circulación de ideas en torno a los procesos de reforma y funcionamiento de los sistemas de justicia ${ }^{71}$. En este lugar estos actores promueven su expertise asociada a la implementación de reformas, rescatando la experiencia obtenida en el proceso chileno.

Por otra parte, a partir del proceso de reforma, la Facultad de Derecho de la Universidad Diego Portales vino a ser la principal facultad de derecho entre las universidades privadas en Chile, promoviendo una serie de cursos y formaciones asociados a esta reforma, lo que a la vez le ha permitido ser una alternativa a las facultades tradicionales dominantes. Riego y Duce utilizan este espacio permanentemente como tribuna en el campo jurídico nacional al cual, en la actualidad, se les suma Vargas dirigiendo esta Facultad en tanto nuevo decano.

A nivel nacional, a partir de la incorporación de ideas provenientes del espacio internacional y de enfoques de modernización en políticas públicas, estos juristas han construido una expertise que pone énfasis en la eficiencia en justicia penal, con un carácter pragmático y flexible, no dogmático. Actualmente, esta expertise que promueven les permite posicionarse en el espacio de discusión técnico-

68 Entrevista realizada en enero de 2007.

69 Como Director Académico de CEJA y actualmente nombrado el nuevo Director Ejecutivo, sucediendo a Vargas en este cargo.

70 Es el actual Director del Programa de Capacitación de CEJA.

71 Un ejemplo de esto es la Revista Sistemas Judiciales, editada conjuntamente por CEJA y el Instituto de Estudios Comparados en Ciencias Penales y Sociales (INECIP) (con sede central en Buenos Aires y tres sedes en América Latina y el Caribe). Sus directores son Juan Enrique Vargas y Alberto Binder, y cuenta con un comité editorial formado por expertos en políticas judiciales en América Latina. Ver http:// www.cejamericas.org 
política del sistema y en el espacio de la discusión académica de interpretación y producción del derecho en Chile.

Esto se expresa en los actuales debates existentes en el espacio nacional, respecto de las promesas que traía aparejadas esta reforma, en relación con el respeto de garantías y sobre todo a la eficiencia en la persecución penal de este nuevo sistema. En este debate esta posición pragmática y técnica se expresa en proposiciones que mezclan enfoques de eficiencia en la gestión del sistema con elementos propios del derecho. Esta expertise se traduce a sus vez en posiciones críticas hacia las visiones por ellos calificadas de más dogmáticas de las garantías al interior del proceso, ya sea por parte de la academia o de los propios operadores del sistema (como lo ha sido respecto de algunos jueces de garantía).

Hoy en día dicha expertise no se encuentra libre de contestación. Por un lado, se encuentra con la oposición natural de los grupos tradicionales que desde un principio se opusieron al proceso de reforma y, por otro lado, con los planteamientos de los otros juristas que participaron del proceso pero que representan una expertise o capital jurídico diferente y que en la actualidad, a partir de la propia dinámica del campo, se encuentran en posiciones opuestas, como es en el caso de María Inés Horvitz y Jorge Bofill.

Así, en los instantes en que se gesta la RPP, estos juristas, junto a Riego y Vargas principalmente, compartían ciertos atributos que les hacían tener una posición similar en el espacio jurídico como lo eran: su juventud; su oposición respecto del procesalismo tradicional y la movilización de conocimientos en derecho procesal penal diferentes del dominante en Chile; la búsqueda de un espacio en el cual desarrollar su actividad académica; y compartir un diagnóstico crítico sobre los problemas del antiguo sistema de enjuiciamiento criminal. Ahora bien, con el proceso de instalación de la RPP, la estructura del campo jurídico o del subcampo de la justicia criminal se transforma. Ya no está presente la cuestión de la oposición al sistema anterior, puesto que se estaba consolidando la RPP y cada uno de los agentes que participó en este proceso obtuvo una mejor posición en el campo jurídico a partir del prestigio asociado a ser parte de quienes gestaron este proceso. Desde la implementación de la reforma comienza a aparecer la discusión sobre el rumbo de este nuevo proceso y su evolución, que, asociado a las discusiones sobre la seguridad ciudadana en Chile, ponen a la RPP y la cuestión del equilibrio de las garantías y la eficiencia del sistema en el centro del debate político y público. En esta dinámica, los elementos estructurantes de la posición que estos agentes ocupaban en el campo jurídico cambian y las visiones diferentes sobre el sistema acusatorio que estos juristas tenían y que durante la gestación de la RPP aparecían sólo como matices al interior de este grupo, una vez instalado este nuevo sistema, se tornan importantes y estructuran posiciones diferentes.

Así por ejemplo, María Inés Horvitz y Jorge Bofill, quienes participaron en el equipo que redactó el código, rescatan un enfoque cercano al derecho procesal europeo y principalmente del alemán. Para ellos, en la discusión de las garantías y eficiencia del sistema penal, no pueden modificarse las instituciones que aseguran los derechos de las personas a partir de la consideración de aspectos asociados 
a visiones pragmáticas que privilegian la sustentabilidad del sistema como son, en cierta medida, las posiciones sostenidas por Riego, Vargas y Duce. Horvitz y Bofill rescatan el rol y centralidad de la dogmática como ciencia del derecho, lo que les lleva a realizar proposiciones que rescatan el sistema de garantías ${ }^{72}$ en la evaluación del sistema y funcionamiento de sus instituciones por sobre otras consideraciones.

Esta diferencia de posición se acompaña, a su vez, de los espacios institucionales distintos en que estos juristas llevan a cabo su labor. Así Horvitz y Bofill se dedican a la práctica profesional del derecho y a la labor académica en la Universidad de Chile, que si bien representa el espacio tradicional, mantiene su estatus como una de las escuelas de derecho más importantes de Chile. En el caso de Horvitz, esta diferencia se expresa en su producción intelectual, generando publicaciones que se sitúan en enfoques opuestos a los promulgados por Riego, Vargas y Duce ${ }^{73}$.

A su vez, estas diferencias se expresan en cuanto a la relación con los operadores del sistema jurídico. Por ejemplo, algunos de los actores cuyas decisiones puntuales han sido criticadas por Riego, Vargas y Duce corresponden a un conjunto de jueces que han participado en diplomados dirigidos por Horvitz en la Universidad de Chile o que pueden identificarse como cercanos a los enfoques y espacio académico en el que ella se desempeña.

No obstante lo anterior, Vargas, Riego y Duce pudieron mantener una posición importante como asesores del Estado en materias relacionadas con el proceso penal, utilizando el espacio de la UDP y CEJA. En este aspecto, CEJA aparece como un lugar importante para su posicionamiento interno, pues el formar parte de ella los legitima internamente al presentarlos como expertos y asesores internacionales

La posición de ventaja que representa CEJA en la trayectoria de estos juristas fortalece su posición de consultores, de "emprendedores simbólicos". Este espacio les permite consolidar su internacionalización, que reconocen como un elemento importante en su validación. Desde allí conducen distintas instancias de discusión con la comunidad jurídica, pero como un espacio que ellos controlan y en el cual han realizado una importante inversión, lo que es percibido así por parte de los juristas que participan de la discusión académica nacional.

Por otra parte, en CEJA estos actores se validan a partir de la experiencia nacional de promoción de la RPP, la que se constituye como un capital que les permite participar en el espacio regional latinoamericano de las reformas de justicia, exportando una experiencia que siendo local nace de la incorporación y traducción de ideas adquiridas en el espacio internacional.

72 Entrevistas realizadas en noviembre de 2007.

73 Por ejemplo, para Horvitz el tipo de análisis que realizan Riego y Duce agrega elementos que no son propios al derecho. Y al contrario, para estos últimos la producción de esta jurista aparecería inspirada en un enfoque dogmático, "tradicional". 
La reforma procesal penal en Chile: nuevos agentes, sus trayectorias...

\section{Conclusiones}

En este artículo se propuso contribuir al análisis de los procesos de reforma de la justicia, intentando superar las visiones que simplifican tales procesos como imposiciones externas o como el resultado de la evolución natural de los sistemas jurídicos modernos.

El análisis propuesto parte considerando la relación existente entre los procesos de carácter estructural, más general, con las trayectorias específicas de los juristas que promovieron la RPP en Chile. Así, la trayectoria inicial de estos juristas se comprende a partir del estado del campo jurídico y la posición que en él ellos ocupaban, en un contexto político marcado por los últimos años de la dictadura y la transición democrática en Chile. Así la trayectoria inicial de estos agentes estará marcada por su incorporación al mundo de juristas que trabajan en torno a la transición democrática en Chile, lo que posibilita posteriormente su inserción en espacios institucionales desde los cuales desarrollarán el trabajo tendiente a la promoción de la RPP.

La promoción inicial de la reforma consiste en una estrategia de construcción de consensos, que considera la estructura del campo jurídico y político que habían obstaculizado los proyectos de reforma de justicia del primer gobierno de la Concertación. De esta manera tal estrategia fue utilizada para brindar la legitimidad técnica y política que esta propuesta de reforma de la justicia criminal requería.

En el análisis de esta estrategia se muestra a su vez cómo la importación de ideas forma parte importante en la construcción de la legitimidad de la propuesta de la reforma, al tiempo que se pone acento en la estructura de poder del campo jurídico en un momento dado. Esta importación de ideas y la incorporación de enfoques de modernización en política pública y judicial, que están directamente ligadas a las estrategias y trayectorias de los agentes analizados, se traduce en la construcción de un capital jurídico diferente al mundo del derecho tradicional, del cual los agentes analizados no formaban parte. Así se muestra cómo este capital brinda una legitimidad técnica a los agentes de la reforma, lo que les permite posicionarse mejor en el espacio jurídico y político y, de esta manera, promover la RPP.

Enseguida el texto presentó a la RPP en continuidad y ruptura con la agenda tomada por el primer gobierno de la Concertación y la promovida por USAID ${ }^{74}$. Dicha agenda respondía a un momento específico de convergencia de estrategias entre el norte y el sur, que se expresa en la promoción de la democracia, la gobernabilidad y la Rule of Law como parte de la politica exterior de EE.UU. y las estrategias internas de agentes locales en su competencia por el poder de Estado en Chile, pero que no estaba teniendo los resultados esperados en momentos en que se presenta la propuesta de reforma del sistema de enjuiciamiento criminal.

74 Es importante señalar que en la actualidad a reforma procesal penal ha sido incorporada en la agenda de cooperación de EE.UU. Tal es el caso de Colombia y México, donde el rol de la cooperación norteamericana ha sido muy activo tanto en la definición de la agenda de reforma como en sus contenidos. 
Esta continuidad y diferencia están dadas en que, si bien los agentes que promovieron la RPP se insertaron inicialmente en el espacio de los juristas que construyen la primera agenda de la Concertación, dicha incorporación les permitió iniciar una trayectoria en la que construyen su propia agenda, distinta de la dominante en ese momento.

De esta manera los agentes de la RPP se constituyen en un relevo generacional de los juristas que generan la agenda de justicia de la transición. Éstos, a partir del limitado alcance de la primera agenda de reformas de la Concertación y la legitimidad técnico y política de la cual habían rodeado la proposición de RPP, logran posicionar esta reforma como iniciativa del segundo gobierno de la Concertación y negociar con USAID la incorporación de esta reforma en su agenda de cooperación con el proyecto CPU.

Finalmente, el texto mostró cómo a partir de una trayectoria determinada y en interacción con un campo jurídico y un contexto político determinados, los agentes que promueven la RPP obtienen una expertise y legitimidad que es el resultado de la interacción del espacio internacional con el local, en un movimiento de ida y vuelta que forma parte de sus estrategias de promoción de la reforma en el espacio local. De esta forma se observa cómo esta expertise y legitimidad permiten a los agentes de la reforma participar en el espacio regional de reforma de la justicia, a cuya transformación y estructuración éstos han contribuido.

\section{Bibliografía}

Asociación de Política Criminal. 1991. Documentos 1991. Santiago: Universidad Diego Portales.

Binder, Alberto y Obando, Jorge. 2004. De las "Repúblicas Aéreas" al Estado de Derecho. Buenos Aires: Editorial Ad-Hoc.

Bourdieu, Pierre. 1986. "La force du Droit. Eléments pour une sociologie du champ juridique". Actes de la Recherche en Sciences Sociales 64: 3-19.

BourdieU, Pierre. 1994. Raisons pratiques. Sur la théorie de l'action. Paris: Éditions du Seuil.

Bourdieu, Pierre y Boltanski, Luc. 1976. "La Production de l'Idéologie Dominante". Actes de la Recherche en Sciences Sociales 2-3: 4-73.

CUADROS, DANIELA. 2003. "Formation et reformulation d'une cause. Le cas des droits de l'homme au Chili, de la dictature à la politique de réconciliation nationale". Politix 62 (16): 165-190.

CuAdros, DANiEla. 2006. "La Commission Rettig. Innovation, Silences et Contestations d'une mise en Récit "consensuelle" des violations de l'homme au Chili". In Après le conflit la réconciliation?, editado por S. Lefranc. Paris: Michel Houdiard éditeur, 208218.

De LA BARRA, Rodrigo. 1999. "Sistema Inquisitivo versus Adversarial: Cultura legal y Perspectivas de la Reforma Procesal Penal en Chile”. Ius et Praxis 2 (5ªño): 139-191.

DeZAlay, Yves y GarTh, BRYANT. 1998. "Chile: Law and the Legitimation Transitions: From the Patrimonial the International Neo-Liberal State". Working Paper Series \# 9709. Chicago: American Bar Foundation. 
La reforma procesal penal en Chile: nuevos agentes, sus trayectorias...

Dezalay, Yves y Garth, Bryant. 2002. La Mondialisation de Guerres de Palais. La Restructuration du Pouvoir d'Etat en Amérique Latine, entre Notables du Droit et "Chicago Boys". Paris: Seuil.

Duce, Mauricio. 2004. "La Reforma Procesal Penal Chilena: Gestación y Estado de Avance de un Proceso de Transformación en Marcha". En: En Busca de una Justicia Distinta. Experiencias de Reforma en América Latina, editado por L. Pásara. Lima: Justicia Viva, 195-248.

Engelmann, Fabiano. 2006. Sociologia do Campo Juridico. Juristas e usos do directo. Porto Alegre: Antonio Fabris Editor.

FAÚNDEZ, JULIO y PÁSARA, LUIS. 2007. "Los Actores Internacionales en el Proceso de Reforma". Ponencia presentada en la Conferencia Internacional Law and Society in the 21st Century (25-28 July). Berlín: Humbolt University.

HilbinK, LisA. 2007. Judges beyond Politics in Democracy and Dictatorship. Lessons from Chile. New York: Cambridge University Press.

LANGER, MÁXIMO. 2004. "From Legal Transplants to Legal Translations: The Globalization of Plea Bargaining and the Americanization Thesis in Criminal Procedure". Harvard International Law Journal I (45): 1-64.

LANGer, MÁXIMO. 2007. "Revolution in Latin American Criminal Procedure: Diffusion of Legal Ideas from the Periphery". American J. of Comparative Law Vol. 55: 617-676.

Madsen, Mikael R., y Dezalay, Yves. 2002. "The Power of the Legal Field: Pierre Bourdieu and the Law". In An Introduction to law and Social Theory, editado por R. Banakar y M. Travers. Oxford: Hart Publishing. 189-204.

MAIER, JULIO y TAVOLARI, RAÚL. 1993. Reformas procesales en América Latina: la oralidad en los procesos. Santiago: Corporación de Promoción Universitaria CPU.

Palacios, DANiEl. 2006. La Genèse de la Reforme de la Procédure Pénale Chilienne. Memoria para optar al título de Master en Ciencias Sociales y Políticas mención Sociología del Derecho. Paris: Universidad Paris 2 Panthéon-Assas.

PÁSARA, LUIS. 2002. "Justicia y Ciudadanía Realmente Existentes". Politica y Gobierno 2 (IX): 316-402.

Peña, CARlos. 1992 "Poder Judicial y Sistema Político. Las Políticas de Modernización". En: Cuadernos de Análisis Jurídico $N^{\circ} 22$. El Poder judicial en la Encrucijada, editado por Carlos Peña et al. Santiago: Universidad Diego Portales, 1 1-55.

Peña, Carlos. 1994. "Hacia una Caracterización del Ethos Legal: De Nuevo sobre la Cultura Jurídica Chilena". En: Evolución de la Cultura Jurídica Chilena, editado por Agustín Squella. Santiago: Corporación de Promoción Universitaria CPU, 23-149.

PuryeAr, JefFrey M. 1994. Thinking politics. Intellectual and Democracy in Chile, 19731988. Baltimore: The Johns Hopkins University Press.

Riego, Cristián. 2005. "El Proceso de Reforma del Procedimiento Penal Chileno". En: Anuario de Derecho Penal 2004. Lima: Asociación Peruana de Derecho Penal.

TOPALOV, CHRISTIAN ed. 1999. Laboratoires du nouveau siècle. La nébuleuse réformatrice et ses réseaux en France 1880-1914. Paris: Editions de l'EHESS.

UrzÚA, Paulina. 2000. "El Uso del Conocimiento en la Reforma Procesal Penal". Estudios Sociales 103(ler trimestre): 111-172.

VAldivieso, Patricio y VARgas JuAn EnRiQue. 2003. "Cambios en el Sistema de Justicia y Sociedad Civil en Chile (1990 - 2002)”. En: Justicia y Sociedad, El Papel de la Sociedad Civil en la Reforma Judicial: Estudios de Caso en Argentina, Chile, Colombia y Perú, editado por L. Pásara et al. Buenos Aires: INECIP, 149-244.

VARGAS, JUAN ENRIQUe (1997) "La Reforma al Sistema de Justicia Criminal en Chile: El Cambio del Rol Estatal”. Estudio de Caso $n^{\circ} 23$. Magíster en Gestión y Políticas Públicas, Departamento de Ingeniería Industrial, Universidad de Chile. Santiago. 
VArgas, Juan EnriQue. 1998. "La Reforma al Sistema de Justicia Criminal en Chile: E1 Cambio del rol Estatal". En: Cuadernos de Análisis Jurídico N³8: La Reforma de la Justicia Penal, editado por M. Duce et al. Santiago: Universidad Diego Portales

VAUCHEZ, ANTOINE y WILLEMEZ, LAURENT. 2004. La justice face à ses réformateurs (19802006). Paris: Presses Universitaires de France PUF. Francia

VIRGOUR, CÉCILE. 2006. "Justice: l'Introduction d'une Rationalité Managériale comme Euphémisation des Enjeux Politiques”. Droit et société: 63-64425-455. Paris. Francia 
La reforma procesal penal en Chile: nuevos agentes, sus trayectorias...

\section{Anexo}

\section{Cronología}

\begin{tabular}{|c|c|}
\hline 1982 & Fundación de Universidad Diego Portales UDP. \\
\hline 1989 & Plebiscito en el que se pone término a la dictadura de Pinochet. \\
\hline 1989 & $\begin{array}{l}\text { Creación del proyecto "Capacitación, Gestión y Política Judicial" en la Corporación } \\
\text { de Promoción Universitaria (CPU), con el financiamiento de USAID. }\end{array}$ \\
\hline $1990-1994$ & $\begin{array}{l}\text { Primer Gobierno de la "Concertación de Partidos por la Democracia", después de la } \\
\text { dictadura del General Pinochet. }\end{array}$ \\
\hline 1991 & $\begin{array}{l}\text { Creación del Departamento de Investigaciones jurídicas en la UDP, el que después } \\
\text { pasará a ser el Centro de Investigaciones Jurídicas (CIJ). }\end{array}$ \\
\hline 1991 & $\begin{array}{l}\text { Obtención de un nuevo financiamiento de USAID para el proyecto "Capacitación, } \\
\text { Gestión y Politica Judicial" de CPU. }\end{array}$ \\
\hline 1992 & Creación de la Fundación Paz Ciudadana (FPC) \\
\hline 1992 & $\begin{array}{l}\text { Seminario "Reformas procesales en América Latina y su impacto en la modernización } \\
\text { de la gestión de los tribunales: La oralidad de los procesos", organizado por CPU, la } \\
\text { Facultad de Derecho de la UDP y la Facultad de Derecho de la Universidad de Valpa- } \\
\text { raíso. Ésta fue una actividad clave para el inicio de la estrategia de la RPP. }\end{array}$ \\
\hline 1993 & $\begin{array}{l}\text { Primera sesión del "Foro por la Oralidad de los Procesos". Primer espacio técnico/ } \\
\text { político en el que se examinaron propuestas de reforma para la justicia criminal. Este } \\
\text { foro es el antecedente directo de las instancias de trabajo en que se realizaron las } \\
\text { propuestas concretas de reforma. }\end{array}$ \\
\hline 1993 & $\begin{array}{l}\text { A partir de la experiencia del foro, la CPU obtuvo una extensión del financiamiento } \\
\text { de USAID. }\end{array}$ \\
\hline 1994 & $\begin{array}{l}\text { Firma de un convenio de trabajo conjunto entre la CPU y la FPC para implementar una } \\
\text { estrategia para promover la RPP. }\end{array}$ \\
\hline 1994 & $\begin{array}{l}\text { Transformación del "Foro por la Oralidad de los Procesos" en "Foro de la Reforma } \\
\text { Procesal Penal", el que contaba con un equipo de dirección y un equipo técnico. A } \\
\text { partir del trabajo de este Foro se diseña un proyecto de reforma del código procesal } \\
\text { penal que será posteriormente recogido por el gobierno. }\end{array}$ \\
\hline $1994-2000$ & Segundo gobierno de la Concertación, con el presidente Eduardo Frei Ruiz-Tagle. \\
\hline 1994 & $\begin{array}{l}\text { Firma de un protocolo de acuerdo entre CPU, FPC y el Ministerio de Justicia para llevar } \\
\text { a cabo, en conjunto, la RPP. }\end{array}$ \\
\hline 1995 & $\begin{array}{l}\text { El presidente Frei presenta al parlamento el proyecto de ley sobre el "Nuevo Código } \\
\text { procesal Penal". }\end{array}$ \\
\hline 1999 & Creación del Centro de Estudios de Justicia de las Américas, CEJA \\
\hline 2000 & Nombramiento de Juan Enrique Vargas como el primer director ejecutivo de CEJA. \\
\hline 2000 & $\begin{array}{l}\text { Inicio de la implementación gradual de la RPP, comenzando por dos de las trece regio- } \\
\text { nes que existian en ese momento en Chile. }\end{array}$ \\
\hline 2005 & $\begin{array}{l}\text { Con la inclusión de la Región Metropolitana, donde se encuentra Santiago, la capital } \\
\text { de Chile, se termina la implementación progresiva de la RPP. }\end{array}$ \\
\hline
\end{tabular}

